\title{
Survey on prevacuum high-pressure steam sterilizers
}

\author{
E. M. DAR MADY, S. E. DREWETT, AND K. E. A. HUGHES
}

From the Portsmouth and Isle of Wight Pathological Service

SYNOPSIS None of the 10 prevacuum high-pressure sterilizers of different makes tested was able to produce and maintain the conditions advocated by the Medical Research Council working parti on high-pressure steam sterilizers (1959) or by Knox and Penikett (1958) with the result that stean did not penetrate adequately the single challenge load and it was not sterilized.

The sterilization of 'group drums' of various sizes and contents was erratic and tended to give operators a false sense of security.

An alarming number of minor engineering faults were present in seven out of 10 machines teste and they require very much more skilled maintenance than is being given at the moment. The possibility of centralizing sterilizers to central sterile supply departments and placing them under the care of a regional engineer cannot be too highly recommended. The presence of undetecte $\Phi$ 'leaks' and a failure to draw a prevacuum of $20 \mathrm{~mm}$. even with a steam burst interferes with.

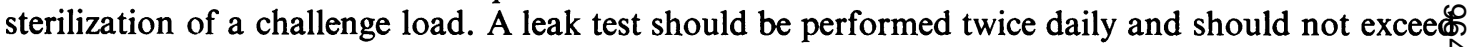
more than $1 \mathrm{~mm}$. in one minute at $20 \mathrm{~mm}$. absolute. The centre of the load should be monitored by crossed tapes or Brownes tubes in each sterilizing cycle. Although the challenge load was sterilizee when the chamber was filled to capacity, a more reliable cycle consisting of a double prevacuun of $20 \mathrm{~mm}$. or more with intermediate steam burst to $10 \mathrm{lb}$. ensured the sterilizing of a single challenge load, which could be adequately controlled by the chamber drain temperature.

In 1958, Knox and Penikett stressed the importance of an initial vacuum before steam sterilization of dressings. They stated that, provided an initial vacuum of $20 \mathrm{~mm}$. absolute was reached, steam penetrated instantaneously to all parts of the load, and that as a result a shortened and more reliable cycle of sterilization could be achieved. In view of these findings the Wessex Regional Hospital Board decided that each management committee in the Wessex Region should be equipped with one prevacuum high-pressure steam sterilizer and that these should be obtained from different manufacturers. During the summer of 1962 it was decided to carry out a survey of these machines to determine their sterilizing ability, and this report records our findings.

The Medical Research Council working party on high-pressure steam sterilizers recommended that to ensure sterilization dressings should receive steam treatment at one of the following time/temperature combinations: three minutes at $134^{\circ} \mathrm{C} .(30 \mathrm{lb} . / \mathrm{sq}$. in. $)$, 10 minutes at $126^{\circ} \mathrm{C}$. $(20 \mathrm{lb} . / \mathrm{sq}$. in. $)$, or 15 minutes at $121^{\circ} \mathrm{C}$. (15 lb./sq. in.).

Received for publication 9 September 1963.
It was further suggested by Knox and Peniket (1958) that the temperature taken in the discharge line, provided that a prevacuum of $20 \mathrm{~mm}$. absolute had been attained, gave a reliable indication of the temperature achieved in the load and therefore the sterilizing cycle was controlled by the discharge line temperature in all the machines tested. I practice, however, most bacteriologists in the Wesseo Region had found that it was necessary to prolong the holding time at the highest temperature since spore tests in test drums indicated that exposure for the recommended time was not a guarantee of sterilization.

\section{METHOD OF TESTINC}

A challenge load consisting of 29 towels in a rectangula British Standard casket was used in each test (Bowie 1961 ; Bowie, Kelsey, and Thompson, 1963). Temperatureo recordings were obtained with thermocouples from foup sites: 1 From the centre of the fifteenth towel inside th $\vec{\Phi}$ casket; 2 from the inside of the wall of the casket approximately the same level; 3 in the chamber drain; $\$$ either in the chamber itself or in the 'group test drume The thermocouples were connected to a direct reading 
Ellab galvanometer fitted with a cold junction compensating device. Temperatures were normally read at halfminute intervals. Brownes tubes (yellow spot) were also placed at sites 1 and 2 . In addition crossed heat-sensitive tapes at the fifteenth towel enabled the degree of steam penetration to be assessed. The degree of vacuum was estimated by a simple mercury $U$ tube.

\section{BACTERIOLOGY}

Two test tubes, $75 \times 12 \mathrm{~mm}$., lightly plugged with cotton wool, laid parallel with the side of the casket, one containing two $B$. stearothermophilus spore papers (Oxoid) and the second dried earth (Lacey), were used at sites 1 and 2 to ascertain the effectiveness of sterilization.

\section{TEST PROCEDURE}

Two standard tests were applied to each machine. The sterilizing cycle as practised in each group was applied first to the challenge load consisting of the standard casket and in addition on seven occasions a drum ("the group drum'), which was locally packed and used as the routine control by that group, and second to the standard casket when the sterilizer had been loaded to capacity.

During the course of the investigation it was found to be imperative to ensure that there were no leaks. This was done by drawing a vacuum of approximately $20 \mathrm{~mm}$. and stopping the cycle by shutting off the pump (a fall of less than $10 \mathrm{~mm}$. in 10 minutes was regarded as satisfactory). The importance of detecting a leak cannot be too highly emphasized, and will be discussed later.

\section{RESULTS}

The results of the tests on the prevacuum highpressure sterilizers are shown in Table I. In addition to those in the Wessex Region two from the South East and one from the South West Metropolitan Regional Hospital Boards are included. Owing to the serious defects found in some sterilizers when first examined further visits and tests were undertaken after engineering maintenance had been carried out.

\section{TABLE I}

RESULTS OF EFFICIENCY TESTS ON 10 PREVACUUM HIGHPRESSURE STERILIZERS

\begin{tabular}{|c|c|c|c|c|c|}
\hline \multirow{3}{*}{$\begin{array}{l}\text { No. of } \\
\text { Sterilizers } \\
\text { Tested on }\end{array}$} & \multicolumn{3}{|c|}{ Sterilized } & \multirow{3}{*}{$\begin{array}{l}\text { No. of } \\
\text { Sterilizers } \\
\text { Leaking }\end{array}$} & \multirow{3}{*}{$\begin{array}{l}\text { No. of } \\
\text { Sterilizers } \\
\text { with } \\
\text { Inadequate } \\
\text { Vacuum }\end{array}$} \\
\hline & \multicolumn{2}{|c|}{$\begin{array}{l}\text { Casket }+ \text { Group } \\
\text { Drum Only }\end{array}$} & \multirow[t]{2}{*}{$\begin{array}{l}\text { Casket + } \\
\text { Full Load }\end{array}$} & & \\
\hline & Casket & $\begin{array}{l}\text { Group } \\
\text { Drum }\end{array}$ & & & \\
\hline $\begin{array}{l}\text { First visit } \\
10\end{array}$ & $0 / 10$ & $6 / 7$ & $3 / 10$ & $5 / 10$ & $2 / 10$ \\
\hline $\begin{array}{l}\text { Subsequent } \\
\text { visits } \\
5\end{array}$ & $0 / 5$ & $\begin{array}{l}\text { Not } \\
\text { tested }\end{array}$ & $5 / 5$ & $0 / 5$ & $0 / 5$ \\
\hline
\end{tabular}

STERILIZING CYCLES FOR A SINGLE CASKET WITH OR WITHOUT GROUP DRUM In seven out of 10 sterilizers the cycle in use was ostensibly that advocated by Knox and Penikett (1958), i.e., a prevacuum of 20 $\mathrm{mm}$. followed immediately by the steaming cycle. In each case the timing of the holding or sterilizing period was taken from the discharge line and was held for the period of time and temperature advocated by the Medical Research Council's working party.

In one of the other three the cycle had been modified so that a prevacuum of $20 \mathrm{~mm}$. was held for nine minutes before the sterilizing cycle commenced. In the two others as soon as the vacuum of $20 \mathrm{~mm}$. was reached either steam was allowed to enter so that the vacuum was reduced to $50 \mathrm{~mm}$., or a continual steam bleed was instituted which was then followed by a further prevacuum of $20 \mathrm{~mm}$., the remainder of the cycle being as first described.

In none of the sterilizers was it possible to sterilize the challenge load although six out of seven of the group test drums were satisfactory. The reason for this was not difficult to determine since the drums were purposely smaller than others in order not to take up too much room in the chamber and were often not packed to the same degree of density. The results stress the false sense of security given by using drums of too small dimensions.

FULL LOAD For this test the sterilizer was filled to capacity with dressings, drums, or packs with the challenge load placed in the lowest part of the chamber near the door. The cycles were as before.

Perhaps one of the most disturbing features was the fact that only three out of 10 were able to sterilize the challenge load when the chamber was filled to capacity. Table II gives the causes of the failures.

\section{TABLE II}

CAUSES OF FAILURE TO STERILIZE TEST CASKET WITH FULLY LOADED CHAMBER

\begin{tabular}{lc} 
Cause of Failure & $\begin{array}{l}\text { No. of } \\
\text { Occasions }\end{array}$ \\
\hline Leaking gaskets & 2 \\
Leaking gasket masked by pump & 1 \\
Valve failures & 2 \\
Pump failures & 2 \\
Total & 7
\end{tabular}

Of the seven which proved to be unsatisfactory, five were found to be leaking. In another the type of water ring pump used was unable to draw a vacuum of greater than $100 \mathrm{~mm}$. and in fact no cycle was found to ensure sterilization of the challenge load. In the seventh the pump setting had been altered so that the sterilizing cycle commenced without reaching $20 \mathrm{~mm}$. absolute; in fact it only achieved $38 \mathrm{~mm}$. Therefore neither complied with the recommendations of Knox and Penikett or of the M.R.C. working party. 
CAUSE OF THE LEAK In three of the sterilizers the leak could be traced to faulty door gaskets. One had such a powerful pump that it was capable of drawing $11 \mathrm{~mm}$. absolute in the face of a serious leak; nevertheless, there was a failure to sterilize the challenge load.

In two the valves failed to operate satisfactorily. In the first a nut had become detached so that although the valve went through the appropriate movements the air inlet was only partially sealed. It was not clear how long it had been in this condition.

In the second, although the pump was capable of drawing $20 \mathrm{~mm}$. or better, the valve operated so slowly between the prevacuum and sterilizing cycle that the air was allowed to enter and the vacuum fell to approximately $100 \mathrm{~mm}$. before the steam sterilizing cycle commenced.

In five instances it was possible to retest in sterilizers after the engineer had corrected the faults. All were now found to be leak proof and well capable of sterilizing the challenge casket when there was a full load but not when the casket was the only package present. It is clear that the importance of ensuring that there is no leak has been underestimated, in spite of the fact that this was emphasized by Bowie (1961) and by Fallon (1961).

STERILIZATION CYCLE IN RELATION TO SINGLE PACKAGE OR CHALLENGE LOAD The fact that hospitals may sometimes need to sterilize only one or two drums at a time suggests that it is essential to design a cycle which will overcome the effect created by the small package.

Bowie (1961) has claimed that the single challenge casket can be sterilized by drawing a prevacuum of at least $20 \mathrm{~mm}$. in less than three minutes and holding it for eight to 10 minutes. As a result residual air is removed and steam penetration is instantaneous. The required holding period can therefore begin at once.

In order to test this hypothesis a prevacuum holding stage was also included. Table III shows the effect of holding the vacuum for five, 10 , and 15 minutes respectively at $20 \mathrm{~mm}$. or less when only the challenge load was included. It is seen that results were equivocal.

In Tables III and IV the result of each sterilizing cycle is indicated by a sign. A negative sign (-) shows that neither thermocouple reading, Brownes tubes, nor crossed tapes indicated steam or heat penetration nor were the spores killed at site 1 . Plus or minus $( \pm)$ indicates that either heat penetration was inadequate but spores were killed, or that the spores were not killed even though heat penetration seemed adequate and that the results were therefore equivocal. The positive sign $(+)$ indicates that heat
TABLE III

EFFECT OF PROLONGATION OF PREVACUUM

\begin{tabular}{|c|c|c|c|c|}
\hline \multirow[t]{2}{*}{ Sterilizer No. } & \multicolumn{4}{|c|}{ Vacuum of $20 \mathrm{~mm}$. Held for } \\
\hline & 5 Minutes & 10 Minutes & 15 & Minute \\
\hline 1 & - & - & - & \\
\hline 2 & - & + & + & \\
\hline 3 & $\ldots$ & - & - & \\
\hline 4 & -. & + & + & \\
\hline 7 & + & Not tested & & t test \\
\hline
\end{tabular}

TABLE IV

EFFECT OF DOUBLE VACUUM OF 20 MM. WITH INTERPOSED STEAM BURST

\begin{tabular}{lll} 
Sterilizer & Steam to & Steam to \\
Number & Atmospheric Pressure & 5 lb. p.s.i. \\
\hline No. & &
\end{tabular}

No. 1

(21 cu. ft.)

(leak)

+ (leak)

No. 2

(24 cu. ft.)

No. 3

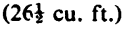

No. 4

(28 cu. ft.)

No. 5

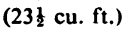

No. 6

(80 cu. ft.)

No. 7

(15 cu. ft.)

(leak)

No. 8

(15 cu. ft.)

No. 9

(86 cu. ft.)

No. 10

(21 cu. ft.)

(steam bleed)

Symbols are as in Table III

penetration was satisfactory and that the spores were destroyed.

For example, although in sterilizers nos. 2 and it was possible to sterilize after holding the pre vacuum for 10 minutes or more, it was not possibles

to do this in sterilizers nos. 1 and 3.
It is obvious from the result obtained that, evenu when leaks are excluded, holding the vacuum of $20 \mathrm{~mm}$. or less is so unreliable that it cannot ensure immediate steam penetration into single packages.

PREVACUUM FOLLOWED BY A STEAM BURST Wilkinson̆ and Peacock (1961) and Henfrey (1961) have botb5 shown that (1) a prevacuum of $20 \mathrm{~mm}$. with a con $\vec{\oplus}$ tinuous steam bleed or (2) a prevacuum of $20 \mathrm{~mm}$ ? followed by a steam burst to atmospheric pressurf with a further vacuum of $20 \mathrm{~mm}$. or less ensures instant penetration of steam to the centre of a single 
challenge package. It should be added that the latter cycle has been used for yarn setting in the artificial fibre industry for a number of years.

The results show that although in the majority of cases the challenge load was sterilized by a steam burst to atmospheric pressure, a more reliable result could be obtained by one to $5 \mathrm{lb}$. or possibly $10 \mathrm{lb}$. pressure even in the presence of a leak.

\section{DISCUSSION}

Our survey again emphasizes the importance of team work in the control of sterilizers; the fact that seven out of 10 steam sterilizers required engineering attention suggests that a regional engineer with suitable knowledge should be put in charge of all sterilizers. Many of the smaller groups are not able to employ engineers of adequate calibre to control the many engineering problems in modern hospitals and this again suggests that centralized sterile supply departments with high-pressure sterilizers provided with proper engineering maintenance would ensure that at least sterility had been achieved.

It is clear that undetected air leaks as already stressed by Bowie (1961) and Fallon (1961) may be a real source of danger. The sterilizer with a powerful pump capable of drawing $11 \mathrm{~mm}$. vacuum in the presence of an air leak can lure the operator into a false sense of security, as can also the sterilizer which draws a satisfactory vacuum of better than $20 \mathrm{~mm}$. but has a faulty valve which allows air to leak back into the chamber, thus preventing steam penetrating to the centre of the load.

Quite apart from the two problems mentioned above it seems that one of the major difficulties of prevacuum high-pressure sterilizers is to ensure that there are no faulty gaskets or inadequate non-return valves. The latter may be prevented from working by a small piece of grit or a wisp of cotton wool.

At present the detection of an air leak can only be determined by a holding test before the sterilizing run but this does not guarantee that a leak may not develop during the cycle. To overcome this Bowie (1961) has suggested an integrator sensing temperature from within the load to control the sterilizing cycle; but Fallon (1961) criticized the integrator and has suggested a semi-permanent artificial load, from which the sterilizing cycle can be controlled, as being more practical. More recently Henfrey (1962) in a personal communication has suggested a permanent sensing device which will simulate conditions inside the standard test casket and from which the steriliz- ing cycle can be controlled. If this can be perfected it should be possible to adapt these machines accordingly. Furthermore, as sterilizers become smaller in capacity a permanent artificial load will occupy valuable chamber space. While an integrator is clearly satisfactory for testing purposes it becomes cumbersome and difficult to operate in practice.

It is also clear from our experience that the holding of a vacuum as recommended by Bowie (1961) does not ensure the sterilization of a single package. From experience gained here the most reliable cycle has proved to be the double vacuum, with intermediate steam burst to $10 \mathrm{lb}$. pressure. Indeed this cycle has also overcome small leaks.

The importance of providing accurate gauges to measure the vacuum cannot be too highly stressed as can be seen by the example of sterilizers nos. 6 and 8 , the former never being able to reach $20 \mathrm{~mm}$. and the latter never able to sterilize the single challenge load even with a steam burst of $10 \mathrm{lb}$. The fact that steam would not penetrate to the casket suggests that downward displacement sterilizers are no longer acceptable if this type of load is to be sterilized.

Nevertheless if an adequate vacuum can be obtained and leaks excluded, the double vacuum with intermediate steam burst of $10 \mathrm{lb}$. sterilizing cycle can be reliably controlled by the discharge line temperature.

This survey shows that undetected leaks and a failure to draw an adequate vacuum will prevent sterilization. It suggests that a more rigorous day-today control is required. It is recommended, therefore, first that the apparatus should be tested twice daily for leaks and not more than $1 \mathrm{~mm}$. in one minute allowed, and second that each load should carry either a Brownes tube or crossed tapes as recommended by Bowie, Kelsey, and Thompson (1963).

Our thanks are due to the Wessex Regional Hospital Board for financial and other support in this project.

\section{REFERENCES}

Bowie, J. H. (1961). In Recent Developments in the Sterilization of Surgical Materials: Report of a Symposium organised by the Pharmaceutical Society, etc., pp. 109-142. Pharmaceutical Press, London.

, Kelsey, J. C., and Thompson, G. R. (1963). Lancet, 1, 586.

Fallon, R. J. (1961). J. clin. Path., 14, 666.

Henfrey, K. M. (1961). The Hospital Engineer, 15, 260.

- (1962). Personal communication.

Knox, R., and Penikett, E. J. K. (1958). Brit. med. J., 1, 680.

Medical Research Council Working Party on Pressure-Steam Sterilisers. (1959). Lancet, 1, 425.

Wilkinson, G. R., and Peacock, F. G. (1961). J. Pharm. Pharmacol., 13 (Suppl.), 67. 